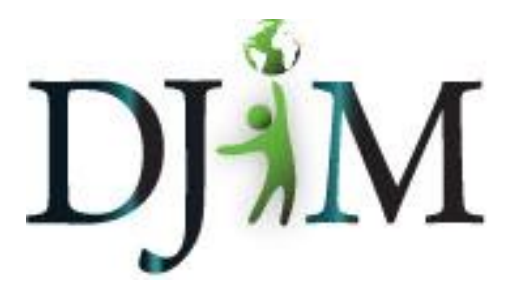

Volume 6 - Spring 2010 djim.management.dal.ca

\title{
Breeding Baby Bureaucracies: Essential factors for the effective development of new organizations
}

\begin{abstract}
New government organizations face a range of challenges in establishing themselves during and after their initial creation. Without proper consideration, these challenges can hamper organizational development or even cause it to collapse altogether. This paper seeks to identify these challenges in order to explore the strengths and weaknesses of new organizations and to investigate how best to use this knowledge to ensure the successful development of new organizations. This will be accomplished through the discussion of past experiences and the exploration of literature on organizational development. Research points to a set of key criteria that help to reinforce organizations over the course of their development, mitigate potential threats, and establish organizations both internally and within their broader environment. These criteria include the development of a clear organizational objective, support from other institutions, exceptional leadership, and effective use of time. The best practices established here may serve as a framework for the development of new organizations in the future.
\end{abstract}

\begin{abstract}
About the Author: Eric Snow is a first year Master of Public Administration student at Dalhousie University. He graduated with a bachelor's degree in Political Science, also from Dalhousie, in 2009. Born and raised in Nova Scotia, Eric is an avid follower of Canadian and international politics and also has academic interests in organizational design and the role of information technology in the public sector. Outside of the classroom, Eric is an active member of the Dalhousie community, working in particular with the Dalhousie Association of Graduate Students (DAGS) and the Dalhousie Student Union (DSU). This paper was written as part of the requirements for the Organizational Design for Governance and Public Management course.
\end{abstract}




\section{Introduction}

Louis Henri Sullivan is credited with first arguing that form should follow function. He argued that structures should be designed specifically for the purpose they were meant to serve (Sullivan, 1896). This principle can be applied to organizational design in the same way that an intended purpose is built into a building's architectural design. However, while a clear objective may be a necessary criterion for a new organization to be effective, it is not, by itself, a sufficient one. In addition to clear objectives, new organizations require broad institutional support, exceptional leadership, and time in order to develop into effective structures capable of fulfilling their mandates. This paper will consider each of these factors in turn and conclude with a consideration of general practices for the creation and development of new organizations.

\section{Clear objective}

When establishing an organizational mandate three questions must be answered: what that mandate is, how it will be achieved, and what outcomes will constitute success. When the answers to these questions are unclear, the dichotomous nature of competing interests can cause internal organizational divisions, which in turn will undermine the effectiveness of the organization in the long run.

To answer what their mandate is, new organizations must have their overall objectives clearly and specifically outlined. This allows the organization to frame the work that it does in the context of a broader mandate. If there is insufficient clarity, the organization can flounder as it struggles internally with competing perspectives on what the mandate truly is. The Ontario Ministry of Community Services suffered from a lack of a clear mandate after its creation. The organization was provided with two mandates, but certain details differed between the two; while the second mandate was introduced as legislation, it was never called for a second reading in the legislature (Klassen, 1996, p. 122). The lack of a legitimate mandate signed into law caused confusion in the department's approach to policy. Particularly, the policy division was unclear as to whether its focus should have been economic or social policy. Klassen rephrased the question for the organization: "should [it] primarily target individuals who would take best advantage of government training funds to become better trained, or... focus on the most disadvantaged individuals with little labour-market attachment?" (Klassen, 1996, p. 123). Without a clear mandate, organizations risk internal conflict due to differing perspectives and may fail to yield the outcomes that their creators originally intended.

The next question to consider relates to how the organization will work to achieve its objectives. In many cases, this is the reason why organizations have their own policy divisions. However, insufficient internal cohesion between the policy and implementation divisions of the organization can lead to ineffective practices. For example, Public Safety Canada has a mandate to "coordinate and support the effort of federal organizations ensuring 
national security and the safety of Canadians... [and] work with other levels of government, first responders, community groups, the private sector and other nations" (Public Safety Canada, 2009). As a result, the department relies heavily on a variety of organizations outside of their direct control for implementation of the policies they create. A report of the auditor general states that the department "has not exercised the leadership necessary to coordinate emergency management activities" (Auditor General, 2009, p. 2). The gulf between the policy and implementation organizations of Public Safety Canada has diminished the ability of the organization to meet its mandate.

The Ontario Ministry of Skills Development is another example of the need for a clear approach to achieving objectives. In this case, there was a divide between the ministry's policy and operations divisions, with each one viewing the other as a barrier to achieving its objectives. While the policy division considered the minister and cabinet to be its clients, the operations division was focused on the trainees and employers (Klassen, 1996, p. 127). While this may not have been an insurmountable challenge in another organization, Skills Development was too new to have established an internal system of common values that could have mitigated the confrontations between divisions. The problem was exacerbated by the fact that the divisions were located in different downtown buildings, greatly reducing the potential for positive, informal interaction between the respective staffs (Klassen, 1996, p. 126). This issue will also be considered later for its time-related implications.

Finally, effective organizations must consider what will constitute success in achieving their mandate. Competing notions of success can give rise to conflict, even if the objective appears to be clearly defined. For example, Malloy argues that in an advocacy context, bureaucrats define their effectiveness based on how influential they are: "the power to develop policy, compel coordination and ensure implementation" (Malloy, 1999, p. 268). From the perspective of social actors, on the other hand, representation is the key to effectiveness: "accurate reflection of the goals and diversity of the movement" (Malloy, 1999, p. 269). Malloy points to how the dichotomous relationship between these two notions gave rise to conflict in the Ontario Women's Directorate in the years following its creation. The advocacy structure fell between "the competing expectations and values of the bureaucratic public service and collective social movements" (Malloy, 1999, p. 284). In the case of the Directorate, expectations were further complicated by the fact that they were not internally homogeneous due to the diversity of the women's movement. An understanding of what constitutes success prevents conflicts from competing stakeholders while allowing for performance measurement techniques to keep the organization on track.

An organization's foundation is based on its purpose. Organizations must establish exactly what that purpose is with a clear mandate. From there, they must consider how best to achieve that mandate, dedicating all divisions within the organization to meeting their objectives. Finally, the organization must have a definition of success that corresponds to the perspective of its stakeholders. 


\section{Institutional support}

Government departments do not exist in a vacuum and cannot be treated as such. Their interactions and relationships with other institutions, many of whom will be crucial to their mandate, must be fostered and supported from the beginning. Support should come from both the political and the bureaucratic sides of government.

Many major organizational changes are caused by external shocks or crises, with the changes being part of the political response to the crisis. The Department of Homeland Security in the United States is a prominent contemporary example of this occurrence. Conceived in the aftermath of the September $11^{\text {th }}, 2001$ terrorist attacks, the creation of the department constituted the largest reorganization of the United States federal government since the 1940s (Bush, 2002, p. 519). The Canadian Ministry of Public Safety was also created at that time, in part to parallel the American organizational changes. This approach is politically appealing due to its ability to signal a dramatic government response to the crisis in question, regardless of whether it is the most effective way to resolve the crisis (Klassen, 1996, p. 132). In other cases, the crises themselves are inherently political. The creation of the Ontario Ministry of Skills Development, for example, came as a surprise to key members of cabinet and bureaucrats in 1985. The decision was largely attributed to new Premier Frank Miller as a political decision, particularly after he called an election three days later (Klassen, 1996, p. 121-2). Another example is the Ontario Ministry of Education and Training, which was split into two separate departments under Premier Mike Harris. The split allowed Harris to respond to pressures from his caucus to join cabinet by creating more seats at the table for his supporters (K. Quigley, personal communication, December 1, 2009).

In many cases, political support is a necessary condition in order to trigger the creation of new organizations or to sustain existing ones. However, it is insufficient to ensure the effectiveness of the organization in achieving its objectives. The extent to which political support, such as the support of the corresponding minister, can help achieve effectiveness will be treated as a consideration under leadership.

New organizations must also strive to find their own role within the broader institutional structure of government. Clarity of mandate is essential to achieving this objective. If the objectives and jurisdiction of the organization are unclear, other organizations can become defensive and engage in turf protection to protect their jurisdiction from the encroachment of the new organization. Aucoin argues that such actions "constitute an obstacle to effective coordination" of government (Aucoin, p. 65). Rather, new organizations should establish their own niches of public policy with a focus specific enough to ensure minimal overlap with existing organizations. Fostering this collaborative approach prior to the introduction of the new organization can help others see the newcomer as an ally, rather than a rival. Klassen argues that new organizations are well served when existing institutions have a stake in their ultimate success (Klassen, 1996, p. 133). Establishing these components in advance will allow new 
organizations to build networks early, improve efficiency by reducing overlap in government, and avoid turf wars.

\section{Leadership}

New organizations demand exceptional leadership at the helm to ensure their successful development. Without any history or institutional memory to form a foundation, a new organization can struggle while trying to determine the best approach to tackle its mandate. In many cases, the new structure is designed in part to work on a groundbreaking area of public policy. This is true even in some cases of organizations formed in part from pre-existing structures; the U.S. Department of Homeland Security, Public Safety Canada, and the Ontario Ministry of Skills Development all included policy divisions with a broad, new mandate (Bush, 2002, p. 518), (Auditor General, 2009, p. 2), (Klassen, 1996, p. 123). The leadership of such organizations must be prepared for the challenges of exploring new uncharted regions of public policy.

New organizations can also struggle to build relationships with existing institutions, even if they are receiving institutional support. These organizations must find their place in a system that may have existed for centuries. Newcomers lack connections and influence but will depend upon both in order to succeed. Exceptional leadership can compensate for these deficiencies by bringing in senior officials who have already established personal connections and influence. Klassen argues for "prestigious, appropriate and proven leadership" in new organizations, pointing out that by the time the Ministry of Skills Development obtained such leadership, it was able to do little more than facilitate its decline" (Klassen, 1996, p. 133). Leadership can be demonstrated at the political level, through the corresponding minister, and at the bureaucratic level, through the deputy minister and other senior public servants.

\section{Time}

Time plays a crucial role in the development of new organizations. This is particularly true prior to their creation and during their early stages of development. Even with a clear mandate, institutional support, and exceptional leadership, new organizations will suffer if these factors come too late in the development process. The "birth pains" that organizations endure, if improperly managed, can slow their development or even cause them to collapse altogether.

A certain amount of time is necessary to bring staff together, to allow them to coalesce, and to facilitate the development of the organization's internal culture (Klassen, 1996, p. 132). Despite the pressures and time constraints on government, cultural shifts in organizations cannot be accomplished overnight. Klassen attributes the fall of the Ontario Ministry of Skills Development in part to a failure to allow the organization time to develop a culture (Klassen, 1996, p. 132). This became problematic in the operations division, for example, where many 
individuals were not accustomed to working with a strong policy-driven centre. Combined with poor internal cohesion, this caused the operations division to view the policy division as its enemy (Klassen, 1996, p. 126). If the ministry had taken the time to put individuals from both divisions together and facilitated networking and relationship-building, the confrontations may not have occurred. Other organizations, particularly central agencies, also fit into the development process. Rather than simply letting an organization loose immediately, maintaining connections and support over the development period can be highly beneficial. Aucoin and French argue that "central agencies must collectively advise and support [a] new organization...for at least two years" (Klassen, 1996, p. 133). This will allow the organization to build itself from the ground up in terms of its internal dynamics and external relations.

Coordination of timing can also be either a trigger for or facilitator of organizational change. The aftermath of crises or external shocks can build political will to help facilitate organizational change. Certain milestones within an organizational life cycle, such as the 5-year point or the midpoint in the timeline of a major task, can cause organizations to reflect upon how successful they have been at achieving their goals (Tyre, Perlow, Staudenmayer, Wasson, 1996 , p. 6). While the process is somewhat subjective, timing can help to facilitate organizational change by taking into account factors ranging from auditor reviews and budget cycles to elections and public opinion. For this reason, timing factors should be analyzed on a case-by-case basis.

Sometimes, time simply means giving an organization enough time to stop and think about its structure and mandate in order to ensure it is still on the right track. Several scholars argue that substantive organizational change is unlikely without any break in the workload to allow for consideration (Tyre et al., 1996, p. 8). Furthermore, even if change were to occur without such a break, it is unlikely that it would bring significant improvements without enough time to consider the issues in detail (Tyre et al., 1996, p. 8). Tyre et al. take this argument one step

further by stating that a break "not only enables change by creating some slack time, but actually triggers the change process by shifting the focus of attention from routine activities to potential improvements" (Tyre et al., 1996, p. 8). In contrast to the rush to get a new organization on its feet, recognizing the need for a pause from time to time may allow individuals to recognize and correct problems before they become ingrained in routine and culture.

\section{Conclusions}

Bureaucracies have a tendency to be set in their ways and resistant to change. Routines develop over time, and without any sort of trigger to change them, these routines tend to restrict adaptation (Tyre et al., 1996, p. 8). However, organizational change, including the development of new organizations, is essential for the renewal of the public sector to meet the ever-changing challenges of the modern world. A clear mandate asks the necessary questions organizations must answer to set their direction and internal dynamics. Broad 
institutional support from both political forces and other organizations within and outside the bureaucracy can drive organizational change and help to nurture the development of new organizations. Exceptional leadership can lay the groundwork for new structures and mitigate the weaknesses that new organizations suffer from. Finally, time can become an asset when used to appropriately consider the organizational structure, provide it with internal cohesion, and facilitate corrections of the organization's own mistakes. Maximizing the use of these factors will provide new organizations with the best chance not only to persevere, but to excel at achieving their mandate to the best of their ability. 


\section{References}

Aucoin, P. "Organizational Design for Governance and Public Management". PUAD 5100 Organizational Design for Governance and Public Management course readings. Halifax, NS: Dalhousie University.

Bush, G. W. (2002). "Homeland Security: Creation of a New Agency". Vital Speeches of the Day, 68(17), p.517-519.

CBC News. (2009). Disasters may catch Canada unprepared: AG report. CBC News. Retrieved from http://www.cbc.ca/canada/story/2009/11/03/auditor-generalreport.html

Klassen, T. R. (1996). "Organizational design and precarious values: The rise and fall of the Ontario Ministry of Skills Development". Canadian Public Administration, 39(2), 117135.

Malloy, J. (1999). "What Makes a State Advocacy Structure Effective? Conflicts Between Bureaucratic and Social Movement Criteria". Governance, 12(3), 267-288.

Office of the Auditor General of Canada. (2009). "Chapter 7: Emergency Management - Public Safety Canada". Report of the Auditor General of Canada to the House of Commons, Fall 2009. Ottawa: Minister of Public Works and Government Services Canada.

Public Safety Canada. (November 4, 2009). "About us". Public Safety Canada. Retrieved from http://www.publicsafety.gc.ca/abt/index-eng.aspx

Sullivan, L. H. (1896). The tall office building artistically considered. Lippincott's Magazine, March.

Tyre, M. J., Perlow, L., Staudenmayer, N., \& Wasson, C. (1996). Time as a Trigger for Organizational Change. Cambridge: Massachusetts Institute of Technology. 